\title{
ISOLASI DAN KARAKTERISASI METABOLIT SEKUNDER DARI EKSTRAK ASETON DAUN Macaranga pruinosa BANGKA BELITUNG
}

\author{
Occa Roanisca ${ }^{\text {a }}$, dan Yana M. Syah ${ }^{\text {b }}$ \\ aJurusan Kimia Fakultas Teknik Universitas Bangka Belitung \\ ${ }^{\mathrm{b} J u r u s a n}$ Kimia Fakultas MIPA Institut Teknologi Bandung \\ Email: occaroanisca@gmail.com
}

\begin{abstract}
Macaranga is a large genus in Euphorbiaceae, locally known as "Mahang-mahangan", and consisting about 300 species. Distribution of Macaranga is widespread from Africa and Madagascar in the west to the tropical regions of Asia including Indonesia. Based on previous research of the M. pruinosa, secondary metabolites that have been reported are flavonoid, and stilbenoid derivatives from Borneo. M. pruinosa that grows in South Sumatra produces poilanoat acid (diterpene). Therefore, this research is done to investigate phytochemical constituent of leaves of $M$. pruinosa from Bangka Belitung Islands. Isolation is done by maceration in acetone, separation and purification using vacuum liquid chromatography and radial chromatography. Structure determination were elucidated by ${ }^{1} \mathrm{H}-\mathrm{NMR},{ }^{13} \mathrm{C}-\mathrm{NMR}, 2 \mathrm{D}$ NMR. Two compounds are identified as flavanon derivatives. They are nymphaeol B, and 6farnesil-3',4',5,7-tetrahidroksiflavanon. These compounds are substituted with terphenyl group, known as geranyl $\left(\mathrm{C}_{10}\right)$, and farnesyl $\left(\mathrm{C}_{15}\right)$. Nymphaeol B (1) and compound of 6-farnesil-3', 4', 5,7-tetrahidroksiflavanon (2) have been found in other species of Macaranga. In conclusion, we here acquired two phenolic derivatives substituted by terphenyl groups from acetone extracts of leaves of M. pruinosa from Bangka Belitung. They are nymphaeol B, and 6-farnesil-3',4',5,7tetrahidroksiflavanon. The result showed that M.pruinosa can produce different secondary metabolites depends on where they grow.
\end{abstract}

Keywords: Euphorbiaceae, Macaranga pruinosa, flavanone.

\section{PENDAHULUAN}

Genus Macaranga merupakan genus yang besar dalam famili Euphorbiaceae terdiri dari 300 spesies ${ }^{[1]}$. Genus ini tersebar di daerah tropik mulai dari Afrika Madagaskar bagian barat, hingga wilayah tropik Asia termasuk Indonesia [2]. Penyebaran di Indonesia tersebar di Sumatra, Sulawesi, Kalimantan, Jawa, Halmahera, Bangka, Maluku, dan Papua dikenal dengan nama lokal "Mahangmahangan" ${ }^{[3]}$.

Berdasarkan data penelitian terhadap spesies Macaranga pruinosa, didapatkan metabolit sekunder yang berbeda karena perbedaan habitat spesies tersebut. Macaranga pruinosa yang berasal dari Kalimantan, telah diteliti oleh Syah dan Ghisalbherti pada tahun 2010 dan $2012^{[4,5]}$ terhadap bagian daun diperoleh senyawa turunan fenolik yaitu flavonoid meliputi nimfaeol $C$, makapruinosin $\mathrm{B}$, makapruinosin $\mathrm{C}$, papiriflavonol A, makapruinosin $\mathrm{D}$, makapruinosin $\mathrm{E}$, makapruinosin $\mathrm{F}$, gliasperin A dan stilben makapruinosin A. Sedangkan penelitian terhadap bagian daun $M$. pruinosa yang berasal dari Sumatera Selatan diperoleh senyawa turunan non fenolik kelompok terpenoid asam poilanoat [6]. Hasil penelitian tersebut mengungkapkan bahwa perbedaan habitat dari suatu spesies 
menyebabkan perbedaan metabolit sekunder yang dihasilkan.

Kajian fitokimia terkait perbedaan habitat terhadap spesies Macaranga pruinosa oleh karenanya menarik untuk dilakukan. Pada penelitian ini akan dikaji fitokimia terhadap daun Macaranga pruinosa yang berasal dari Bangka Belitung.

\section{METODOLOGI PENELITIAN}

\section{Preparasi Sampel}

Daun Macaranga pruinosa diperoleh dari provinsi Bangka Belitung. Daun segar yang didapatkan dikeringkan di udara terbuka, setelah itu digiling menjadi serbuk kering $(1 \mathrm{~kg})$.

\section{Bahan dan Alat}

Bahan yang digunakan antara lain serbuk kering daun Macaranga pruinosa, silika gel Merck $60 \mathrm{GF}_{254}$ untuk kromatografi cair vakum (KCV), Si-gel $60 \mathrm{PF}_{254}$, plat KLT Kieselgel $60 \mathrm{GF}_{254} 0,25 \mathrm{~mm}$. Pelarut organik antara lain $\mathrm{MeOH}$, n-heksan, etil asetat, dan aseton, serta pelarut pro analisis kloroform, pereaksi penampak noda larutan $\mathrm{CeSO}_{4}$.

Alat yang digunakan antara lain peralatan gelas, vacuum rotary evaporator, neraca analitik, lampu UV- Vis SSC-5410, kromatotron. Penentuan struktur molekul ditetapkan dengan analisis spektroskopi NMR dengan spektrometer Agilent ${ }^{1} \mathrm{H}$ NMR $500 \mathrm{MHz}$ dan ${ }^{13} \mathrm{C}$ NMR $125 \mathrm{MHz}$, dan dibandingkan dengan data literatur.

\section{Ekstraksi dan Isolasi}

Serbuk kering daun Macaranga pruinosa $(1 \mathrm{~kg})$ dimaserasi selama $3 \times 24$ jam menggunakan pelarut aseton didapatkan ekstrak aseton kering (21,2 gr). Selanjutnya ekstrak aseton difraksinasi dengan menggunakan KCV. Pada fraksinasi ini digunakan eluen campuran n-heksan;etil asetat dengan cara meningkatkan kepolarannya ( $8: 2 ; 7: 3 ; 6,5 ; 2,5 ; 6: 4 ; 1: 1$; (EtOAc) 100\% dan $\mathrm{MeOH}$ ) menghasilkan 13 fraksi A1 - A13. Pemurnian terhadap fraksi A8, A9, dan A10 dilakukan dengan menggunakan kromatotron. Eluen yang digunakan adalah $\mathrm{CHCl}_{3}: \mathrm{MeOH}(50 \mathrm{ml}$ : 1ml), didapatkan fraksi $\mathrm{ACa}-\mathrm{ACz}$. Fraksi $\mathrm{ACi}$ dan $\mathrm{ACj}$ merupakan senyawa murni nimfaeol B (1) sebanyak $8 \mathrm{mg}$. Pemurnian selanjutnya terhadap fraksi A8, A9, dan A10 menggunakan kromatotron menggunakan eluen $\mathrm{CHCl}_{3}: \mathrm{MeOH} \quad(50 \mathrm{ml}: 1 \mathrm{ml})$, menghasilkan fraksi ACa - ACz. Fraksi ACm dan ACn merupakan senyawa murni 6farnesil-3',4',5,7-tetrahidroksiflavanon sebanyak $33 \mathrm{mg}$.

\section{HASIL DAN DISKUSI}

Nimfaeol B didapatkan berupa minyak bewarna coklat dengan rumus molekul $\mathrm{C}_{25} \mathrm{H}_{28} \mathrm{O}_{6}$. Berdasarkan spektrum ${ }^{1} \mathrm{H}-\mathrm{NMR}$ didapatkan tiga sinyal proton dobel doblet pada pergeseran kimia $5,52 \mathrm{ppm}(1 \mathrm{H}, d d, J$ $=2,1$ dan $11,0 \mathrm{~Hz}, \mathrm{H}-2), 3,11 \mathrm{ppm}(1 \mathrm{H}, d d, J$ $=13,4$ dan 17,1Hz, H-3a), dan $2.75 \mathrm{ppm}(1 \mathrm{H}$, $d d, J=2,3$ dan $17,1, \mathrm{H}-3 \mathrm{~b})$ sebagai bukti kerangka flavanon, serta satu sinyal singlet gugus hidroksi terkelasi pada pergeseran kimia 12,07 ppm ${ }^{[7]}$. Pada daerah aromatik terdapat dua sinyal proton doblet pada pergeseran kimia yang lebih deshileding $6,84 \mathrm{ppm}(1 \mathrm{H}, d, J=8,4 \mathrm{~Hz})$ dan $6,97 \mathrm{ppm}$ $(1 \mathrm{H}, d, J=8,4 \mathrm{~Hz})$ menunjukkan pola substitusi berupa tetrasubstituen dengan posisi 2 proton berkopling secara ortho pada cincin B di posisi C-5' dan C-6', sedangkan pada pergeseran kimia yang lebih shielding didapatkan dua sinyal proton doblet yang saling berkopling secara meta $\delta_{\mathrm{H}} 5,97 \mathrm{ppm}$ $(1 \mathrm{H}, d, \quad J=1,7 \mathrm{~Hz})$ dan $6,02 \mathrm{ppm}(1 \mathrm{H}, d, J$ $=1,7)$ merupakan tetrasubstitusi pada cincin A dengan posisi proton pada C-6 dan C-8. Data ${ }^{13} \mathrm{C}$ NMR menunjukkan adanya lima sinyal karbon oksiaril $\delta_{\mathrm{c}}(\mathrm{ppm}): 142,6 ; 144,7$; 163,$3 ; 164,3$; 165,6. Berdasarkan data ${ }^{1} \mathrm{H}-$ NMR dan ${ }^{13} \mathrm{C}$ NMR, diketahui bahwa terdapat substituen di cincin B pada posisi C2'.

Analisis spektrum ${ }^{1} \mathrm{H}-\mathrm{NMR}$ lebih lanjut untuk mengidentifikasi jenis substituen yang terikat pada gugus aromatik di cincin $\mathrm{B}$, didapatkan dua sinyal vinil pada $\delta_{\mathrm{H}}: 5,04$ ppm $(1 \mathrm{H}, t m)$, dan 5,16 ppm $(1 \mathrm{H}, t m)$, satu sinyal metilen doblet $\delta_{\mathrm{H}} 3,46 \mathrm{ppm}$, serta tiga sinyal metil singlet $\delta_{\mathrm{H}}: 1,59 \mathrm{ppm}, 1,67 \mathrm{ppm}$, dan 1,75 ppm jenis substituen tersebut berupa gugus geranil yang tersubstitusi pada posisi C-2' di cincin B. 
Penentuan $\delta_{\mathrm{H}}$ pada gugus farnesil dilakukan dengan melihat korelasi pada spektrum NMR 2 dimensi ${ }^{1} \mathrm{H}^{-1} \mathrm{H}$ COSY. Sinyal vinil $\delta_{\mathrm{H}} 5,16$ ppm (1H, tm, H-2") memiliki korelasi dengan satu sinyal proton metilen $\delta_{\mathrm{H}} 3,46 \mathrm{ppm}(2 \mathrm{H}$, $d, J=6,5 \mathrm{~Hz}, \mathrm{H}-1$ ") dan satu sinyal metil $\delta_{\mathrm{H}}$ $1,75 \mathrm{ppm}(3 \mathrm{H}, s, \mathrm{H}-4$ "). Selanjutnya sinyal vinil $\delta_{\mathrm{H}} 5,04 \mathrm{ppm}(1 \mathrm{H}, \mathrm{tm}, \mathrm{H} 7$ ”) berkorelasi dengan dua sinyal metilen $\delta_{\mathrm{H}} 2,04 \mathrm{ppm}(2 \mathrm{H}$, $m$, H-5") dan 2,07 (2H, $m, \mathrm{H}-6$ "), serta berkorelasi dengan dua sinyal metil $\delta_{\mathrm{H}} 1,59$ ppm (3H, $s, \mathrm{H}-10$ "), dan1,66 ppm $(3 \mathrm{H}, s, \mathrm{H}-$ 9"). Berdasarkan data, senyawa tersebut merupakan nimfaeol B (Gambar 1). Nimfaeol B juga ditemukan pada spesies M.tanarius dan $M$. triloba ${ }^{[8,9,10]}$. Pembuktian letak gugus geranil di cincin $\mathrm{B}$ dilihat dari korelasi HMBC.

Kemungkinan gugus geranil tersubstitusi di cincin B posisi C-2' dibuktikan dari korelasi HMBC. Sinyal proton doblet ortho posisi H$4 \delta_{\mathrm{H}} 6,97 \mathrm{ppm}$ memiliki korelasi dengan $\delta_{\mathrm{c}}$ 76,4 ppm (C-2), 126,3 (C-2'), dan 144,7 ppm (C-4'). Sementara itu sinyal proton metilen doblet gugus geranil $\delta_{\mathrm{H}} 3,46 \mathrm{ppm}$ memiliki korelasi dengan $\delta_{\mathrm{c}} 128,3 \mathrm{ppm}\left(\mathrm{C}-1^{\prime}\right), 126,3$ ppm (C-2'), 121,3 ppm (C-2”), dan 138,3 ppm (C-3"), korelasi sinyal-sinyal tersebut sebagai bukti bahwa gugus geranil tersubstitusi di cincin B posisi C-2'. Korelasi HMBC senyawa nimfaeol B dapat dilihat pada Tabel 1. Untuk perbandingan data ${ }^{1} \mathrm{H}-$ NMR dan ${ }^{13} \mathrm{C}$ NMR nimfaeol B hasil isolasi dengan data literatur ditunjukkan pada Tabel 2.<smiles>CC(C)=C[CH+]CC(C)=C[CH+]c1c([C@@H]2CC(=O)c3c(O)cc(O)cc3O2)ccc(O)c1O</smiles>

(1)

Gambar 1. Senyawa tersebut merupakan nimfaeol B

Tabel 1 Korelasi HMBC antara ${ }^{1} \mathrm{H}$ NMR dengan ${ }^{13} \mathrm{C}$ NMR senyawa (1)

\begin{tabular}{|c|c|c|}
\hline C no. & $\begin{array}{c}\text { Senyawa Hasil Isolasi } \\
\left.\text { (Aseton- } d_{6} 500 \mathrm{MHz}\right) \\
\delta_{\mathrm{H}}(\mathrm{ppm})\end{array}$ & $\begin{array}{c}\text { Korelasi HMBC } \\
\qquad\left({ }^{1} \mathrm{H} \leftrightarrow{ }^{13} \mathrm{C}\right)\end{array}$ \\
\hline 2 & 5,52 & - \\
\hline \multirow[t]{2}{*}{3} & 3,11 & \\
\hline & 2.75 & $\mathrm{C}-2, \mathrm{C}-4$ \\
\hline 5 & 12,07 & C-4a, C-5, C-6 \\
\hline 6 & 6,02 & C-5, C-8 \\
\hline 8 & 5,97 & C-4a, C-6, C-8a \\
\hline 5 & 6,84 & C-1', C-3', C-4' \\
\hline 6 & 6,97 & C-2, C-2', C-4' \\
\hline $1 ”$ & 3,46 & C-1', C-2', , C-2", C-3"' \\
\hline $2 "$ & 5,16 & C-4", C-5" \\
\hline $4 "$ & 1,75 & C-2", C-3", C-5" \\
\hline $5 "$ & 2,04 & C-2", C-3", C-6" \\
\hline $6 "$ & 2,07 & C-5", C-8" \\
\hline $7 ”$ & 5,04 & - \\
\hline $9 ”$ & 1,66 & C-7”, C-8”, C-10" \\
\hline $10 "$ & 1,59 & C-7", C-8", C-9" \\
\hline
\end{tabular}


Tabel 2 Perbandingan data ${ }^{1} \mathrm{H}-\mathrm{NMR}$ dan ${ }^{13} \mathrm{C}$ NMR senyawa (1) hasil isolasi dengan data literature ${ }^{[10]}$.

\begin{tabular}{|c|c|c|c|c|}
\hline \multirow[t]{2}{*}{$\begin{array}{l}\text { C } \\
\text { no. }\end{array}$} & $\begin{array}{c}\text { Nimfaeol B } \\
\\
\left(\text { Aseton- } d_{6} 300 \mathrm{MHz}\right) \\
\delta_{\mathrm{H}} \text { dalam ppm (integrasi, mu }\end{array}$ & isitas, & \multicolumn{2}{|c|}{$\begin{array}{c}\text { Senyawa Hasil Isolasi } \\
\left.\text { (Aseton- } d_{6} 500 \mathrm{MHz}\right) \\
\delta_{\mathrm{H}} \text { dalam ppm (integrasi, multipisitas, } \\
J \text { dalam Hz) dan } \delta_{\mathrm{c}} \text { dalam ppm }\end{array}$} \\
\hline & $\begin{array}{c}J \text { dalam } \mathrm{Hz}_{1} \text { ) dan } \delta_{\mathrm{c}} \text { dalam } \\
{ }^{\mathrm{N}}\end{array}$ & ${ }^{13} \mathrm{C}$ & ${ }^{1} \mathbf{H}$ & ${ }^{13} \mathrm{C}$ \\
\hline 2 & $5,62(1 \mathrm{H}, d d, J=2,7 ; 13,2)$ & 76,3 & $5,52(1 \mathrm{H}, d d, J=2,1 ; 11,0)$ & 76,4 \\
\hline $3 a$ & $3,16(1 \mathrm{H}, d d, J=13,2 ; 17,1)$ & 42,4 & $3,11(1 \mathrm{H}, d d, J=13,4 ; 17,1)$ & 42,6 \\
\hline $3 b$ & $2,66(1 \mathrm{H}, d d, J=2,7 ; 17.1)$ & & $2.75(1 \mathrm{H}, d d, J=2,3 ; 17,1)$ & \\
\hline 4 & - & 196,7 & - & 196,3 \\
\hline $4 \mathrm{a}$ & - & 102,2 & - & 102,7 \\
\hline 5 & $12,20(s,-\mathrm{OH})$ & 164,4 & $12,07(\mathrm{~s},-\mathrm{OH})$ & 164,3 \\
\hline 6 & $5,96(1 \mathrm{H}, s)$ & 95,0 & $6,02(1 \mathrm{H}, d, J=1,7)$ & 96,7 \\
\hline 7 & - & 166,5 & - & 165,6 \\
\hline 8 & $5,96(1 \mathrm{H}, s)$ & 95,9 & $5,97(1 \mathrm{H}, d, J=1,7)$ & 95,6 \\
\hline $8 \mathrm{a}$ & - & 163,8 & - & 163,3 \\
\hline 1 ' & - & 128,9 & - & 128,3 \\
\hline 2 ' & - & 126,8 & - & 126,3 \\
\hline $3^{\prime}$ & - & 143,2 & - & 142,6 \\
\hline $4^{\prime}$ & - & 144,7 & - & 144,7 \\
\hline 5 & $6,82(1 \mathrm{H}, d, J=8,1)$ & 112,6 & $6,84(1 \mathrm{H}, d, J=8,4)$ & 112,9 \\
\hline $6^{\prime}$ & $6,97(1 \mathrm{H}, d, J=8,1)$ & 117,7 & $6,97(1 \mathrm{H}, d, J=8,4)$ & 118,5 \\
\hline $1 "$ & $3,56(2 \mathrm{H}, d, J=6,6)$ & 24,3 & $3,46(2 \mathrm{H}, d, J=6,5)$ & 25,2 \\
\hline $2 "$ & $5,19(1 \mathrm{H}, t d, J=6,6)$ & 123,3 & $5,16(1 \mathrm{H}, \mathrm{tm})$ & 121,3 \\
\hline $3 "$ & - & 134,5 & - & 138,3 \\
\hline $4 "$ & $1,70(3 \mathrm{H}, s)$ & 15,5 & $1,75(3 \mathrm{H}, s)$ & 16,2 \\
\hline $5 "$ & $1,97(2 \mathrm{H}, t, J=6,6)$ & 39,5 & $2,04(2 \mathrm{H}, m)$ & 39,6 \\
\hline $6 "$ & $2,05(2 \mathrm{H}, m)$ & 26,5 & $2,07(2 \mathrm{H}, m)$ & 26,3 \\
\hline $7 ”$ & $5,07(1 \mathrm{H}, d t, J=1,5$ dan 6,5$)$ & 124,2 & $5,04(1 \mathrm{H}, \mathrm{tm})$ & 123,8 \\
\hline $8 "$ & - & 130,9 & - & 132,1 \\
\hline $9 "$ & $1,60(3 \mathrm{H}, s)$ & 24,9 & $1,66(3 \mathrm{H}, s)$ & 25,6 \\
\hline $10 "$ & $1,56(3 \mathrm{H}, s)$ & 16,8 & $1,59(3 \mathrm{H}, s)$ & 17,7 \\
\hline
\end{tabular}

Senyawa 6-farnesil-3',4',5,7-tetrahidroksiflavanon merupakan minyak berwarna coklat dengan rumus moleku $\mathrm{C}_{30} \mathrm{H}_{36} \mathrm{O}_{6}$. Penentuan struktur senyawa tersebut berdasarkan analisa data ${ }^{1} \mathrm{H}-\mathrm{NMR}$ dan ${ }^{13} \mathrm{C}$ NMR. Berdasarkan data spektrum ${ }^{1} \mathrm{H}-\mathrm{NMR}$ didapatkan ciri kerangka flavanon yang ditunjukkan oleh sinyal-sinyal berupa tiga buah dobel doblet, yaitu 3,02 ppm, 2,39 ppm ,dan 5,19 ppm. Ketiga sinyal proton tersebut berkopling secara visinal aksial dengan ekuatorial $(J=$ $2,8 \mathrm{~Hz})$, visinal aksial dengan aksial $(J=12,9$ $\mathrm{Hz})$, dan secara germinal $(J=17,1 \mathrm{~Hz})$, masing - masing untuk $\mathrm{H}-3 \mathrm{a}, \mathrm{H}-3 \mathrm{~b}$, dan $\mathrm{H}-2$ serta satu sinyal proton singlet untuk gugus hidroksi terkelasi pada pergeseran kimia $12,21 \mathrm{ppm}$. Berdasarkan data tersebut kerangka untuk senyawa yang ketiga merupakan kerangka flavanon.

Sinyal-sinyal proton pada cincin aromatik menunjukkan senyawa turunan flavanon memiliki cincin aromatik trisubstitusi dan pentasubstitusi. Sinyal proton yang lebih shielding memiliki $\delta_{\mathrm{H}} 5,94 \mathrm{ppm}$ dengan multiplisitas singlet (cincin A) menunjukkan 
pola substitusi pada cincin A merupakan pentasubstitusi. Sinyal proton lainnya yang lebih deshielding memiliki tiga sinyal proton berpola $\mathrm{ABX}$ yang ditunjukkan dengan adanya sinyal proton dobel doblet dengan $\delta_{\mathrm{H}}$ $6,78 \mathrm{ppm}$ nilai $J=1,8 \mathrm{~Hz}$ (kopling meta) dan $J=8,2 \mathrm{~Hz}$ (kopling ortho), sinyal proton doblet pada $\delta_{\mathrm{H}} 6,81 \mathrm{ppm}$ nilai $J=8,2 \mathrm{~Hz}$ (kopling orto), serta satu sinyal proton doblet dengan $\delta_{\mathrm{H}} 6,92 \mathrm{ppm}$ nilai $J=1,6 \mathrm{~Hz}$ (kopling meta). Sinyal tersebut untuk cincin B trisubstitusi senyawa turunan flavanon. Spektrum ${ }^{13} \mathrm{C}$ NMR menujukkan adanya sinyal karbon oksiaril sebanyak lima buah pada $\delta_{\mathrm{c}}(\mathrm{ppm}): 144,4 ; 144,9 ; 161,1 ; 161,3$; 164,3. Berdasarkan sinyal spektrum ${ }^{1} \mathrm{H}-$ NMR, ${ }^{13} \mathrm{C}$ NMR dan pola oksigenasi yang lazim bahwa terdapat substituen selain gugus hidroksi pada cincin A aromatik.

Penentuan jenis substituen dilakukan dengan mengidentifikasi sinyal-sinyal proton pada daerah alifatik. Pada daerah tersebut didapatkan sejumlah sinyal proton pada pergeseran kimia 5,05 ppm, 5,06 ppm, dan $5,21 \mathrm{ppm}$. Sinyal untuk tiga buah vinil, $\delta_{\mathrm{H}}$ 3,46 ppm sinyal satu buah metilen doblet, serta $\delta_{\mathrm{H}} 1,55 \mathrm{ppm}, 1,56 \mathrm{ppm}, 1,64 \mathrm{ppm}, 1,78$ ppm merupakan sinyal empat buah metil singlet. Data sinyal proton menunjukkan jenis substituen yang terikat pada cincin A berupa gugus farnesil. Penentuan letak gugus farnesil ditentukan dengan melihat korelasi pada spektrum HMBC.

Analisis terhadap spektrum HMBC untuk mengetahui posisi gugus farnesil pada cincin A dengan melihat korelasi proton yang terkelasi. Proton yang terkelasi memiliki korelasi yang berjarak 2 ikatan dengan 161,3 ppm (C-5), korelasi berjarak 3 ikatan dengan $\delta_{\mathrm{c}} 102,4$ ppm (C-4a) dan 108,5 ppm (C-6). Data tersebut menunjukkan bahwa proton yang terkelasi berkorelasi dengan 3 karbon kuartener, bearti gugus farnesil berada pada posisi C-6 dicincin A aromatik. Data HMBC secara keseluruhan dapat dilihat pada Tabel 3.

Tabel 3 Korelasi HMBC antara ${ }^{1} \mathrm{H}$ NMR dengan ${ }^{13} \mathrm{C}$ NMR 6-farnesil-3', 4',5,7 Tetrahidroksiflavanon (2)

\begin{tabular}{|c|c|c|}
\hline C no. & $\begin{array}{c}\text { Senyawa Hasil Isolasi } \\
\left.\text { (Aseton- } d_{6} 500 \mathrm{MHz}\right) \\
\delta_{\mathrm{H}}(\mathrm{ppm}) \\
\end{array}$ & $\begin{array}{c}\text { Korelasi HMBC } \\
\quad\left({ }^{1} \mathrm{H} \leftrightarrow{ }^{13} \mathrm{C}\right)\end{array}$ \\
\hline 2 & 5,19 & - \\
\hline \multirow[t]{2}{*}{3} & 3,02 & \\
\hline & 2,39 & C-2, C-4, C-1' \\
\hline 5 & 12,21 & C-4a, C-5, C-6 \\
\hline 8 & 5,94 & C-4a, C-6, C-7, C-8a \\
\hline $2^{\prime}$ & 6,92 & C-2, C-3', C-4', C-6' \\
\hline 5 & 6,81 & C-1', C-3', C-4' \\
\hline $6^{\prime}$ & 6,78 & $\mathrm{C}-2, \mathrm{C}-2^{\prime}, \mathrm{C}-4^{\prime}$ \\
\hline $1 "$ & 3,46 & C-5, C-6, C-7, C-2",C-3" \\
\hline $2 "$ & 5,21 & C-4", C-5" \\
\hline $4 "$ & 1,78 & C-2", C-3", C-5" \\
\hline $5 "$ & 1,93 & C-2", C-4", C-6", C-7" \\
\hline $6 "$ & 2,04 & C-5", C-7", C-8" \\
\hline $7 "$ & 5,05 & C-6", C-9" \\
\hline $9 ”$ & 1,55 & C-7", C-8" C-10" \\
\hline $10 ”$ & 1,92 & C-7", C-8", C-10" \\
\hline $11 ”$ & 1,99 & C-10", C-12" \\
\hline $12 ”$ & 5,06 & C-10", C-11" \\
\hline $14 "$ & 1,64 & C-13", C-15" \\
\hline $15 "$ & 1,56 & C-13", C-14" \\
\hline
\end{tabular}


Tabel 4 Perbandingan data ${ }^{1} \mathrm{H}-\mathrm{NMR}$ dan ${ }^{13} \mathrm{C}$ NMR untuk senyawa 6-farnesil-3', $4^{\prime}, 5,7$ tetrahidroksiflavanon (2) hasil isolasi dengan data literatur ${ }^{[10]}$

\begin{tabular}{|c|c|c|c|c|}
\hline \multirow[t]{2}{*}{$\begin{array}{c}\mathrm{C} \\
\text { no. }\end{array}$} & \multicolumn{2}{|c|}{$\begin{array}{c}\text { 6-farnesil-3', } 4^{\prime}, 5,7- \\
\text { tetrahidroksiflavanon } \\
\left.\text { (Aseton- } d_{6} 300 \mathrm{MHz}\right) \\
\delta_{\mathrm{H}}(\text { integrasi, multipisitas, } J \text { dalam Hz) }\end{array}$} & \multicolumn{2}{|c|}{$\begin{array}{c}\text { Senyawa Hasil Isolasi } \\
\left.\text { (Aseton- } d_{6} 500 \mathrm{MHz}\right) \\
\delta_{\mathrm{H}}(\text { integrasi, multipisitas, } J \text { dalam } \mathrm{Hz})\end{array}$} \\
\hline & ${ }^{1} \mathbf{H}$ & ${ }^{13} \mathrm{C}$ & ${ }^{1} \mathbf{H}$ & ${ }^{13} \mathrm{C}$ \\
\hline 2 & $5,35(1 \mathrm{H}, \mathrm{dd}, J=3,0 ; 12,6)$ & 79,0 & $5,19(1 \mathrm{H}, d d, J=2,8 ; 12,9)$ & 78,9 \\
\hline 3 & $3,11(1 \mathrm{H}, \mathrm{dd}, J=12,6 ; 17,1)$ & 42,8 & $3,02(1 \mathrm{H}, d d, J=12,9 ; 17,1 \mathrm{~Hz})$ & 42,9 \\
\hline & $2,71(1 \mathrm{H}, \mathrm{dd}, J=3,0 ; 17,1)$ & & $2,39(1 \mathrm{H}, d d, J=2,9 ; 17,1 \mathrm{~Hz})$ & \\
\hline 4 & - & 196,4 & - & 196,1 \\
\hline $4 a$ & - & 102,2 & - & 102,4 \\
\hline 5 & $12,47(-\mathrm{OH}, \mathrm{s})$ & 161,1 & $12,21(s,-\mathrm{OH})$ & 161,3 \\
\hline 6 & - & 108,2 & - & 108,5 \\
\hline 7 & - & 164,0 & - & 164,3 \\
\hline 8 & $6,04(1 \mathrm{H}, \mathrm{s})$ & 94,5 & $5,94(1 \mathrm{H}, s)$ & 94,9 \\
\hline $8 \mathrm{a}$ & - & 161,4 & - & 161,1 \\
\hline 1 & - & 130,8 & - & 130,4 \\
\hline 2 & $7,04(1 \mathrm{H}, \mathrm{s})$ & 113,8 & $6,92(1 \mathrm{H}, d, J=1,6)$ & 113,3 \\
\hline $3^{\prime}$ & - & 145,1 & - & 144,4 \\
\hline 4 & - & 145,5 & - & 144,9 \\
\hline 5 & $6,87(1 \mathrm{H}, \mathrm{s})$ & 115,1 & $6,81(1 \mathrm{H}, d, J=8,2)$ & 115,1 \\
\hline 6 & $6,87(1 \mathrm{H}, \mathrm{s})$ & 118,3 & $6,78(1 \mathrm{H}, d d, J=1,8$ dan 8,2$)$ & 118,5 \\
\hline $1 "$ & $3,36(2 \mathrm{H}, \mathrm{d}, J=7,5)$ & 20,7 & $3,46(2 \mathrm{H}, d, J=6,9)$ & 20,9 \\
\hline $2 "$ & $5,28(1 \mathrm{H}, \mathrm{td}, J=6,0)$ & 122,7 & $5,21(1 \mathrm{H}, t m)$ & 121,9 \\
\hline $3 "$ & - & 134,5 & - & 136,1 \\
\hline $4 "$ & $1,79(3 \mathrm{H}, \mathrm{s})$ & 15,4 & $1,78(3 \mathrm{H}, s)$ & 16,1 \\
\hline $5 "$ & $1,95(2 \mathrm{H}, \mathrm{m})$ & 39,6 & $1,93(2 \mathrm{H}, m)$ & 39,7 \\
\hline $6 "$ & $2,00(2 \mathrm{H}, \mathrm{m})$ & 26,6 & $2,04(2 \mathrm{H}, m)$ & 26,5 \\
\hline $7 "$ & $5,12(1 \mathrm{H}, \mathrm{dt}, J=1,2 ; 5,7)$ & 124,1 & $5,05(1 \mathrm{H}, t m)$ & 124,1 \\
\hline $8 "$ & - & 134,0 & - & 134,9 \\
\hline $9 "$ & $1,58(3 \mathrm{H}, \mathrm{s})$ & 15,3 & $1,55(3 \mathrm{H}, s)$ & 15,9 \\
\hline $10 ”$ & $1,95(3 \mathrm{H}, \mathrm{s})$ & 39,6 & $1,92(2 \mathrm{H}, m)$ & 39,6 \\
\hline $11 "$ & $2,00(2 \mathrm{H}, \mathrm{m})$ & 26,4 & $1,99(2 \mathrm{H}, m)$ & 26,6 \\
\hline $12 ”$ & $5,09(1 \mathrm{H}, \mathrm{dt}, J=1,5 ; 5,4)$ & 124,4 & $5,06(1 \mathrm{H}, t m)$ & 124,3 \\
\hline $13 ”$ & - & 130,7 & - & 131,2 \\
\hline $14 "$ & $1,65(3 \mathrm{H}, \mathrm{s})$ & 25,0 & $1,64(3 \mathrm{H}, s)$ & 25,6 \\
\hline $15 "$ & $1,58(3 \mathrm{H}, \mathrm{s})$ & 16,9 & $1,56(3 \mathrm{H}, s)$ & 17,6 \\
\hline
\end{tabular}

Penentuan pergeseran kimia pada substituen gugus farnesil dilihat dari spektrum ${ }^{1} \mathrm{H}-{ }^{1} \mathrm{H}$ COSY. Sinyal proton vinil $\delta_{\mathrm{H}} 5,21 \mathrm{ppm}(\mathrm{H}-$ 2") memiliki korelasi dengan sinyal metilen doblet $\delta_{\mathrm{H}} 3,46 \mathrm{ppm}(\mathrm{H}-1$ ") dan sinyal proton metil singlet $\delta_{\mathrm{H}} 1,78 \mathrm{ppm}(\mathrm{H}-4$ "), Sinyal proton vinil $\delta_{\mathrm{H}} 5,05 \mathrm{ppm}(\mathrm{H}-7$ ") berkorelasi dengan dua sinyal metilen yang memiliki multiplisitas multiplet yaitu 1,93 ppm (H-5") dan 2,04 ppm(H-6") serta satu sinyal metil singlet $\delta_{\mathrm{H}} 1,55 \mathrm{ppm}(\mathrm{H}-9$ "). Sinyal proton vinil $\delta_{\mathrm{H}} \quad 5,06 \mathrm{ppm}$ (H-12") berkorelasi dengan dua sinyal metilen yang multiplet, yaitu 1,92 ppm (H-10") dan 1,99 ppm ( $\mathrm{H}-$ 11 ") dan dua sinyal proton metil singlet $\delta_{\mathrm{H}}$ : 1,56 ppm (H-15") dan 1,64 ppm (H-14"). 
Perbandingan data ${ }^{1} \mathrm{H}-\mathrm{NMR}$ dan ${ }^{13} \mathrm{C}$ NMR untuk senyawa hasil isolasi dengan literatur ditunjukkan pada Tabel 4.

Identifikasi terhadap sinyal-sinyal pada spektrum ${ }^{1} \mathrm{H}-\mathrm{NMR}$ dan ${ }^{13} \mathrm{C}$ NMR bahwa senyawa turunan flavanon untuk senyawa kedua merupakan senyawa 6-farnesil3',4',5,7-tetrahidroksiflavanon (2) yang pernah diisolasi dari spesies $M$. triloba (Gambar 2)

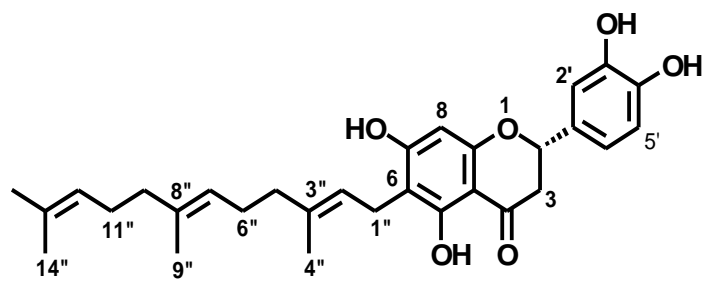

(2)

Gambar 2. Senyawa 6-farnesil-3',4',5,7tetrahidroksiflavanon

\section{KESIMPULAN}

Pada penelitian ini telah berhasil diisolasi dua senyawa turunan flavanon dari ekstrak aseton daun Macaranga pruinosa, yaitu nimfaeol B (1), dan 6-farnesil-3', 4',5,7tetrahidroksiflavanon (2), asal Bangka Belitung. Nimfaeol B dan 6-farnesil-3',4',5,7tetrahidroksiflavanon telah ditemukan pada spesies Macaranga lainnya, yaitu M.tanarius dan $M$. triloba. Hasil penelitian ini menunjukkan bahwa spesies $M$. pruinosa dapat menghasilkan metabolit sekunder berbeda apabila tumbuh di tempat yang berbeda.

\section{DAFTAR PUSTAKA}

1. Fareza, M.S., 2012, Aktivitas Antioksidan, Antibakteri, Dan Antijamur Senyawa Flavonoid dari Daun Macaranga adisca Zoli, Tesis Program Magister, Sekolah Pasca Sarjana, ITB, Bandung.

2. Tanjung, M., Hakim, E.H., Mujahidin, D., Hanafi, M., dan Syah, Y.M., Macagigantin, a Farnesylated Flavonol from Macaranga gigantean, Journal of Asian natural products research, 11(11), pp.929-932 (2009).

3. Heyne, K., 1987, Tumbuhan Berguna Indonesia Edisi 2, Badan Penelitian dan Pengembangan Kehutanan, Departemen Kehutanan, Yayasan Sarana Wana Jaya.

4. Syah, Y.M., dan Ghisalberti, E.L., Phenolic Derivatives with an Irregular Sesquiterpenyl Side Chain from Macaranga pruinosa, Natural product communications, 5(2), pp.219-222 (2010).

5. Syah, Y.M., dan Ghisalberti, E.L., More Phenolic Derivatives with An Irregular Sesquiterpenyl Side Chain from Macaranga pruinosa, Natural product communications, 5(2), pp.45-49 (2012).

6. Mahendra, H., 2010, Asam Poilanoat dari Daun Macaranga pruinosa, Skripsi program S1, Institut Teknoligi Bandung.

7. Ilmiawati, A., 2012, Flavanoid dari Daun Macaranga mappa (Euphorbiaceae) serta Aktivitas Antioksidan dan Sitotoksiknya, Tesis Program Magister, Sekolah Pasca Sarjana, ITB, Bandung.

8. Kawakami, S., Harinantenaina, L., Matsunami, K., Otsuka, H., Shinzato, T., dan Takeda, Y., Macaflavanones A-G, Prenylated Flavanones from the Leaves of Macaranga tanarius, Journal of Natural Products, 71(11), pp.1872-1876 (2008).

9. Tseng, M.H., Kuo, Y.H., Chen, Y.M., dan Chou C.H., Allelopathic Potential of Macaranga tanarius (L.) Muell.-Arg, Journal of Chemical Ecology, 29(5), pp.1269-1286 (2003).

10. Zakaria, I., Ahmat, N., Jaafar, F.M., Widyawaruyanti, A., Flavonoids with Antiplasmodial and Cytotoxic Activities of Macaranga triloba, Fitoterapia, 83(5), pp.968-972 (2012). 